\title{
Doença de Camurati-Engelmann: relato de caso
}

\section{Camurati-Engelmann disease: case report}

\author{
Gisele Cristine Dyonísio Fernandes', Daniela Lima de Souza², \\ Eliane Sayuri Yamada ${ }^{2}$, Érika Renata Motinaga Sunahara², \\ Rita de Cássia Menin ${ }^{3}$, Roberto Acayaba de Toledo ${ }^{4}$
}

\begin{abstract}
Fernandes GCD, Souza DL, Yamada ES, Sunahara ERM, Menin RC, Toledo RA. Doença de Camurati-Engelmann: relato de caso. Rev Med (São Paulo). 2009 jul.-dez.;88(3/4):181-5.

RESUMO: Objetivos: Fornecer informações sobre a doença de Camurati-Engelmann, também conhecida como Displasia Diafisária Progressiva, possibilitando o seu diagnóstico pelo profissional de saúde. Método: Relato de caso associado a revisão da literatura científica sobre o tema. Discussão: Doença rara, de herança autossômica dominante, caracterizada por hiperostose progressiva com envolvimento das diáfises dos ossos. Os sintomas mais comuns são dores em extremidades, alteração da deambulação, fatigalibidade e fraqueza muscular. Seu diagnóstico é clínico-radiológico. O tratamento consiste basicamente na administração de glicocorticóides e anti-inflamatórios não esteroidais para melhorar os sintomas clínicos como dor e fadiga.
\end{abstract}

DESCRITORES: Síndrome de Camurati-Engelmann; Doenças do desenvolvimento ósseo.

INTRODUÇÃO

A doença de Camurati-Engelmann também conhecida como Displasia Diafisária Progressiva, é uma condição rara, mais comum no sexo masculino. Apresenta herança genética autossômica dominante, de penetrância variável, podendo haver história familiar ou ser caso esporádico². O início da doença geralmente é na infância, quase sempre antes dos 30 anos de idade.

\section{MATERIAIS E MÉTODOS}

Revisão de artigos científicos publicados

1. Residente do Serviço de Reumatologia da FAMERP - Faculdade de Medicina de São José do Rio Preto - FAMERP.

2. Acadêmica do 6o ano de Medicina da Faculdade de Medicina de São José do Rio Preto - FAMERP.

3. Professora Assistente do Serviço de Reumatologia do Departamento de Medicina I da Faculdade de Medicina de São José do Rio Preto - FAMERP.

4. Professor Adjunto do Serviço de Reumatologia do Departamento de Medicina I da Faculdade de Medicina de São José do Rio Preto - FAMERP.

Endereço para correspondência: Gisele Cristine Dyonísio Fernandes. Rua Suécia, 1200, apto 92, Bairro Nossa Senhora de Fátima, CEP: 15015-530 - São José do Rio Preto, SP. e-mail: gifernandes60 @ hotmail.com 
sobre doença de Camurati-Engelmann.

\section{RELATO DO CASO}

J.J.G.P., 30 anos, sexo masculino, brasileiro, branco, foi atendido no ambulatório de Reumatologia pela primeira vez em 1995, aos 16 anos, com queixa de dor em membros inferiores há, aproximadamente, seis meses, que piorava aos esforços, associada à fadiga e dificuldade de deambulação. Em seus antecedentes pessoais apresentava história de gestação a termo sem intercorrências no período neonatal, ausência de cosanguinidade entre os pais, desenvolvimento neuropsicomotor normal, correção de Tetralogia de Fallot aos sete anos, correção de criptorquidia à direita aos onze anos e hipoacusia à esquerda. Ausência de história semelhante na família.

Ao exame físico apresentava-se em bom estado geral, sem comprometimento intelectual, com discreta exoftalmia, maxilar proeminente, pavilhões auriculares em abano e com poucas circunvoluções, e hiperplasia de gengiva. Apresentava ainda sopro sistólico em foco aórtico acessório; abdome sem alterações; peso e estatura baixos para a idade; atraso na maturação sexual (Tanner I); marcha arrastada; joelhos em valgo; dor à palpação de terço médio de tíbias; acentuação da lordose lombar com limitação importante da extensão da coluna vertebral.

Apresentava radiografias de fêmur, tíbia, fíbula (Figuras 1, 2 e 3) e úmero com espessamento cortical difuso simétrico, notadamente em diáfises, e hipoplasia de epífises. Radiografia (Figura 4) e tomografia de crânio com esclerose e espessamento ósseo em base de crânio, com envolvimento bilateral e difuso de mastóides. Radiografia de coluna lombar com esclerose das articulações interapofisárias.

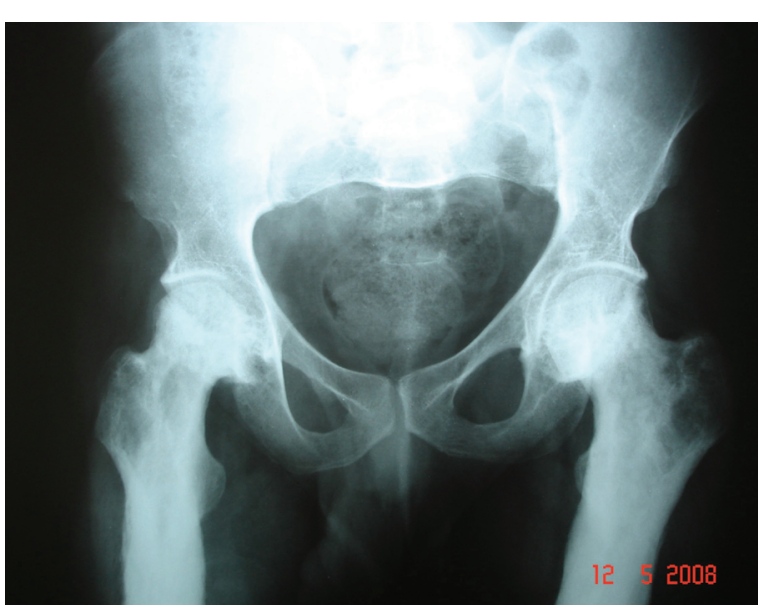

FIGURA 1. Radiografia mostrando espessamento simétrico das corticais das diáfises do fêmur
Cintilografia óssea mostrava hiperconcentração do radioimunoindicador em região de arcos zigomáticos, mastóides, úmeros, ulnas, rádios, fêmures, tíbias e fíbulas.

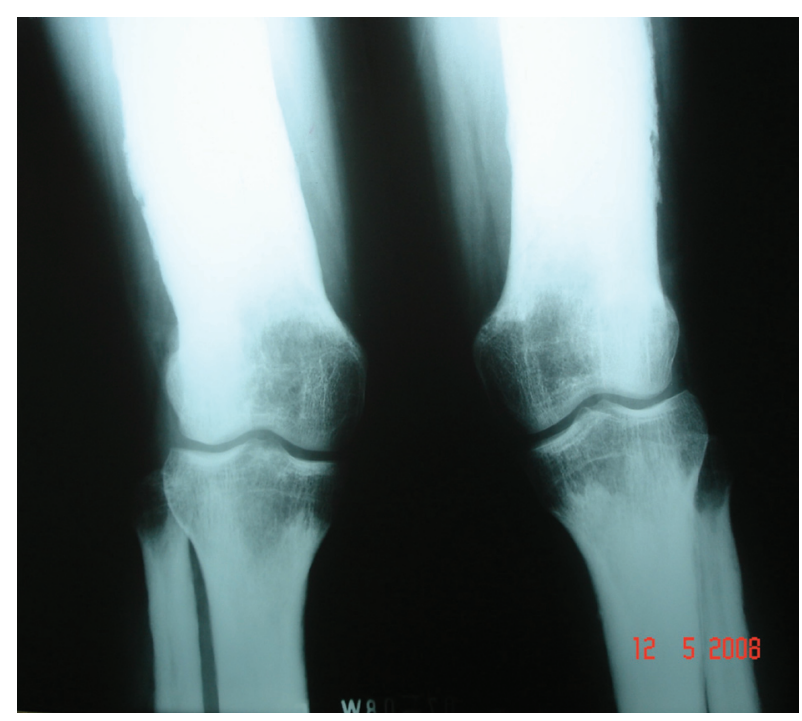

FIGURA 2. Radiografia mostrando espessamento simétrico de diáfises de fêmur, tíbia e fíbula

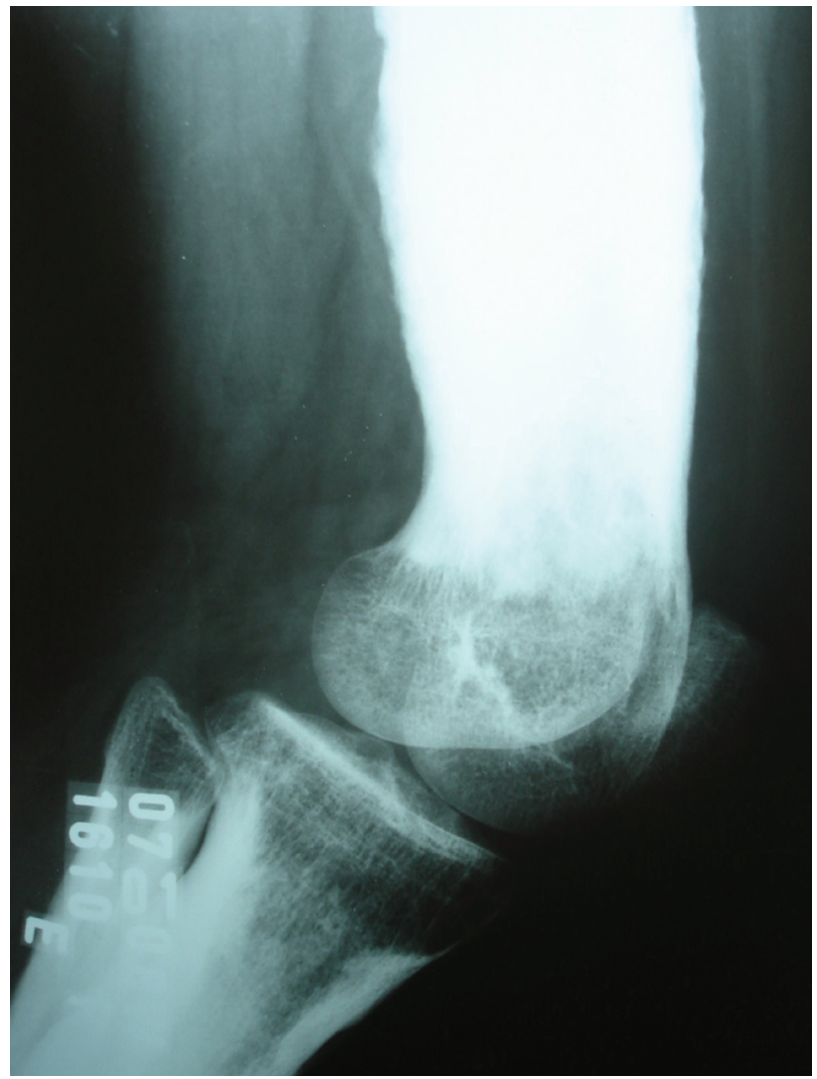

FIGURA 3. Radiografia mostrando espessamento simétrico de diáfises de fêmur, tíbia e fíbula 


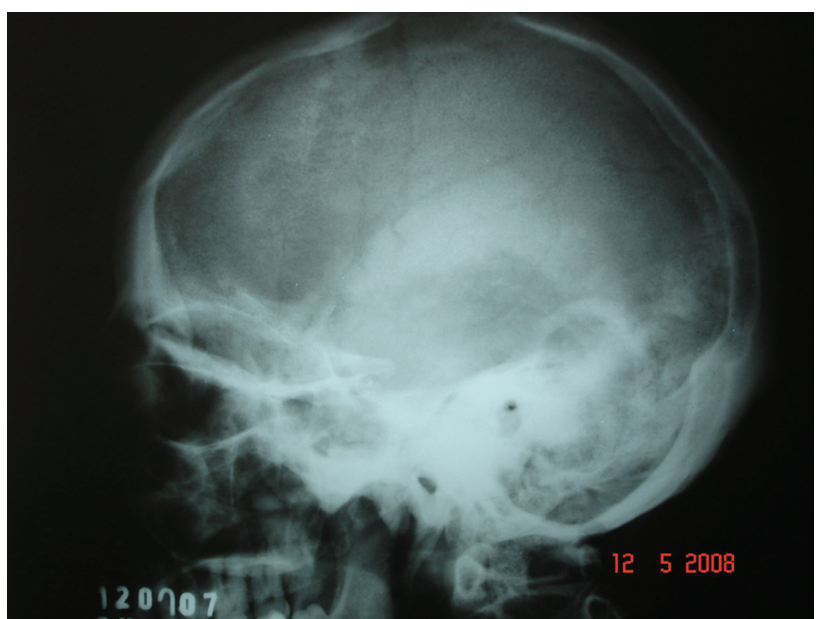

FIGURA 4. Radiografia de crânio mostrando aumento difuso na densidade dos mastóides

Laboratorialmente, apresentava hemoglobina de $11.6 \mathrm{~g} / \mathrm{dl}$ [valor normal $(\mathrm{N})=12$ a $16 \mathrm{~g} / \mathrm{dl}$ ], hematócrito de $35 \%$ [ $\mathrm{N}=40$ a $55 \%$ ], dosagens de creatinofosfoquinase, desidrogenase lática, cálcio total e cálcio ionizado e fósforo normais, aumentos da velocidade de hemossedimentação [1 ${ }^{\text {a }}$ hora $=$ $55 \mathrm{~mm} / \mathrm{h}(\mathrm{N}<5 \mathrm{~mm} / \mathrm{h})]$, Proteína $C$ reativa $[20 \mathrm{mg} /$ $\mathrm{ml}(\mathrm{N}<7 \mathrm{mg} / \mathrm{ml})]$ e fosfatase alcalina [288U/l (N 50 a $136 \mathrm{U} / \mathrm{I})]$.

Os achados clínicos e radiológicos levaram ao diagnóstico de síndrome de Camurati-Engelmann. Paciente passou também por avaliação genética, que foi compatível com a doença.

Foram administrados glicocorticóide (prednisona) e anti-inflamatórios não esteroidais, com remissões temporárias do quadro álgico. O paciente foi encaminhado para avaliação endocrinológica, descartando hipótese diagnóstica de hipogonadismo hipogonadotrófico. Após terapia com esteróide injetável, paciente evoluiu para Tanner V. Atualmente, mantém acompanhamento ambulatorial regular, em uso de baixas doses de anti-inflamatório não esteroidal, mantém queixa de dor em membros inferiores de caráter intermitente. Exames laboratoriais normais, exceto pela manutenção de fosfatase alcalina elevada.

\section{DISCUSSÃO}

A síndrome de Camurati-Engelmann pertence ao grupo das hiperostoses craniotubulares e resulta de uma mutação em um gene localizado no braço longo do cromossomo 19 que codifica o TGF $\beta 1$ (Transforming Growth Factor $\beta 1$ ), um importante mediador do remodelamento ósseo, dando origem à expressão inadequada desta molécula, levando a redução da atividade osteoclástica e aumento da osteoblástica, com predomínio de deposição óssea ${ }^{2,9,23}$. Acredita-se que outros genes, diferentes do TGF $\beta 1$, influenciem também nos resultados da doença, explicando assim a extrema variabilidade na expressão fenotípica ${ }^{3,16,24}$

Esta doença caracteriza-se por formação óssea endosteal e periosteal progressiva e simétrica, levando ao espessamento cortical, estreitamento do canal medular e alargamento diafisário 2,22,23. Acomete principalmente as diáfises do fêmur e tíbia, estendendo-se à fíbula, úmero, ulna e rádio. Com a progressão da doença, as metáfises também podem ser acometidas, mas as epífises são poupadas ${ }^{19}$. Pode haver esclerose de base de crânio e acometimento de outros ossos, como quadril, face, mandíbula, caixa torácica e vértebras, em $20 \%$ dos $\operatorname{casos}^{5,12,16}$

Clinicamente, costuma manifestar-se com dor em membros inferiores, alteração da marcha, fadiga e fraqueza muscular. Manifestações menos comuns são redução dos tecidos adiposo subcutâneo e muscular ${ }^{10}$, o que pode estar relacionado ao TGF $\beta 1$, que age como inibidor da miogênese ${ }^{13}$ e da adipogênese ${ }^{7}$. Pode-se encontrar também exoftalmia, geno varo ou valgo, escoliose, retardo puberal, hipogonadismo, hepatoesplenomegalia, perda auditiva ou visual e paralisia facial por compressão de nervos cranianos no envolvimento da base de crânio 2,12,15,22,23. Fraturas ósseas de baixo impacto são raras ${ }^{11}$.

Radiologicamente, observa-se aumento da densidade e alargamento da cortical das diáfises dos ossos longos, de forma bilateral e simétrica ${ }^{2,23}$. A tomografia computadorizada mostra integridade da musculatura adjacente ${ }^{2}$. A cintilografia óssea mostra captação anormal heterogênea do radiofármaco devido à atividade osteoblástica aumentada. A biópsia óssea não mostra alterações específicas ${ }^{11}$.

Os marcadores bioquímicos de remodelamento ósseo geralmente são normais. Pode haver aumento da velocidade de hemossedimentação, anemia $^{14}$ e leucopenia, porém não há exames laboratoriais específicos para essa doença, sendo o diagnóstico baseado nos achados clínico-radiológicos.

O diagnóstico diferencial deve ser feito com outras displasias que cursam com defeitos de ossificação, como doença de Ribbing-Fairbank (displasia epifisária múltipla), doença de Van Buchen (hiperostose cortical generalizada, que afeta principalmente crânio, mandíbula - com alargamento característico, clavícula e costelas e menos frequentemente a diáfise de ossos longos), displasia craniodiafisária (esclerose generalizada, em particular dos ossos do crânio e face, com anormalidades faciais, estenose de coanas bilateral, obstrução nasal e de ductos lacri- 
mais), displasia fibrosa poliostótica (com progressiva substituição óssea por tecido fibroso) $)^{7,17}$. Deve-se considerar também doença de Paget óssea, osteopetrose (aumento da densidade óssea de forma difusa, acometendo epífise, metáfise e diáfise), situações que podem cursar com dor em membros, além de compressão nervosa ${ }^{1,2,12}$. Em crianças, diferenciar da dor inespecífica de membros, desordens neuromusculares, causas malignas e não orgânicas ${ }^{17}$, que podem se apresentar com quadro clínico semelhante, mas não mostram as alterações ósseas características nas radiografias.

Não há tratamento específico; muitos relatam sucesso com o uso de glicocorticóide, com melhora clínica da dor e fadiga e até melhora da mobilidade, também foram documentadas correções das anormalidades radiológicas. Nos tratamentos em longo prazo a dose do glicocorticóide deve ser diminuída para a menor dose efetiva, estando sempre atento aos conhecidos efeitos colaterais como osteoporose de coluna vertebral, síndrome de Cushing, supressão do crescimento em crianças, alterações neurológicas e psiquiátricas. Os anti-inflamatórios não esteroidais são usados para controle do quadro álgico, mas não promovem melhora nas alterações ósseas. Relatase também o uso de bisfosfonatos, com resultados controversos $^{6,8,10}$. Tratamentos cirúrgicos como a perfuração do canal medular com brocas de diâmetro crescente, para alargamento do canal medular ${ }^{25}$; descompressão de nervo facial; descompressão orbital para remover a invasão óssea do nervo óptico ${ }^{10}$; abordagem do meato acústico interno e realização de implante coclear nas perdas auditivas profundas ${ }^{20}$; são alternativas nos casos com estreitamento de canal medular e compressão nervosa ${ }^{18,20,21}$. Contudo, como se trata de uma doença progressiva, os sintomas podem recorrer ${ }^{10}$. Paciente pode também se beneficiar clinicamente com fisioterapia para fortalecimento muscular.

\section{CONCLUSÃO}

A síndrome de Camurati-Engelmann, apesar de rara, deve ser conhecida e lembrada no diagnóstico diferencial de dor em membros, fraqueza e fadiga.

Fernandes GCD, Souza DL, Yamada ES, Sunahara ERM, Menin RC, Toledo RA. CamuratiEnglemann disease: case report. Rev Med (São Paulo). 2009 jul.-dez.;88(3/4):181-5.

\begin{abstract}
Goals: To provide information about Camurati-Engelmann disease, also known as progressive diaphyseal dysplasia, allowing its diagnosis by a healthcare professional. Methods: A case report associated with literature review. Discussion: It is a rare, autosomal dominant type, disease characterized by progressive hyperostosis involving the diaphysis of bones. The most commom clinical symptoms are pain in extremities, waddling gait, fatigability and muscle weakness. Its diagnosis may be determined by clinical and radiological data. Treatment involves basically glucocorticosteroids and non-steroid anti-inflammatory administration to promote improvement in clinical symptoms such as pain and fatigue.
\end{abstract}

KEY WORDS: Camurati-Engelmann syndrome; Bone diseases, developmental.

\title{
REFERÊNCIAS
}

1. Antunes ML, Testa JRG, Frazatto R, Barberi JAF, Rogério, Silva FND. Osteodistrofias raras do osso temporal. Rev Bras Otorrinolaringol. 2005;71(2):22832.

2. Brat HG, Hamoir $X$, Matthijs $P$, Lambin $P$, Van Campenhoudt M. Camurati-Engelmann disease: a late and sporadic case with metaphyseal involvement. Eur Radiol. 1999;9:159-62.

3. Campos-Xavier B, Saraiva JM, Savarirayan R, Verloes A, Feingold J, Faivre L, et al. Phenotypic variability at the TGFbeta1 locus in Camurati-Engelmann disease. Hum Genet. 2001;109:653-8.
4. de Vernejoul MC. Sclerosing bone disorders. Best Pract Res Clin Rheumatol. 2008;22(1):71-83.

5. Fonte AC, Gonçalves MC, Catalan J, Justino Junior RO. Doença de Camurati-Engelmann: relato de caso com acometimento ósseo grave. Radiol Bras. 2005;38(6):471-2.

6. Iba K, Takada J, Kamasaki H, Oda T, Hatakeyama N, Wada T, et al. A significant improvement in lower limb pain after treatment with alendronate in two cases of Camurati-Engelmann disease. J Bone Miner Metab. 2008;26(1):107-9.

7. Ignotz RA, Massague J. Type beta transforming 
Fernandes GCD, et al. Doença de Camurati-Engelman: relato de caso.

growth factor controls the adipogenic differentiation of 3 T 3 fibroblasts. Proc Natl Acad Sci USA. 1985;82:8530-4.

8. Inaoka $\mathrm{T}$, Shuke $\mathrm{N}$, Sato J, Ishikawa $\mathrm{Y}$, Takahashi $\mathrm{K}$, Aburano $\mathrm{T}$, et al. Scintigraphic evaluation of pamidronate and corticosteroid therapy in a patient with progressive diaphyseal dysplasia (Camurati-Engelmann disease). Clin Nucl Med. 2001;26(8):680-2.

9. Janssens $\mathrm{K}$, ten Dijke $\mathrm{P}$, Janssens $\mathrm{S}$, Van Hul W. Transforming growth factorbeta1 to the bone. Endocr Rev. 2005;26:743-74.

10. Janssens K, Vanhoenacker F, Bonduelle M, Verbruggen L, Van Maldergem L, Ralston S, et al. CamuratiEngelmann disease: review of the clinical, radiological, and molecular data of 24 families and implications for diagnosis and treatment. J Med Genet. 2006;43:1 11.

11. Kaftori JK, Kleinhaus U, Naveh Y. Progressive diaphyseal dysplasia (Camurati-Engelmann): radiographic follow-up and CT findings. Radiology. 1987;164(3):77782.

12. Lang WS, Viterbo BG, Kiy Y, Gérios JC, Curcelli EC. Displasia diafisária progressiva: aspectos radiológicos e cintilográficos - relato de caso. Rev Imagem. 1991:13:17-9.

13. Massague J, Cheifetz S, Endo T, Nadal-Ginard B. Type beta transforming growth factor is an inhibitor of myogenic differentiation. Proc Natl Acad Sci USA. 1986;83:8206-10.

14. Mondal RK, Karmakar B, Chandra PK, Mukherjee K. Ghosal type hemato-diaphyseal dysplasia: a rare variety of Engelmann's disease. Indian J Pediatr. 2007;74(3):291-3.

15. Moumoulidis I, De R, Ramsden R, Moffat D. Unusual otological manifestations in Camurati-Engelmann's disease. J Laryngol Otol. 2006;120(10):892-5.

16. Park SJ, Yoon CS, Park HW, Choi JR, Chung JS, Lee
KA. The first Korean case of Camurati-Engelmann disease (progressive diaphyseal dysplasia) confirmed by TGFB1 gene mutation analysis. J Korean Med Sci. 2009;24(4):737-40.

17. Ramanan AV, Hall MJ, Baildam EM, Mughal Z. Camurati-Engelmann disease-a case report and literature review. Rheumatology. 2005;44(8):1069-72.

18. Simpson RK Jr, Fisher DK, Gall GK, Rose JE. Fatal cerebellar herniation secondary to Camurati-Englemann's disease. J Neurol Neurosurg Psychiatry. 1988;51(10):1349-52.

19. Sparkes RS, Graham CB. Camurati-Engelmann disease. Genetics and clinical manifestations with a review of the literature. J Med Genet. 1972;9:73-85.

20. Tibesar RJ, Brissett AE, Shallop JK, Driscoll CL. Internal auditory canal decompression and cochlear implantation in Camurati-Engelmann disease. Otolaryngol Head Neck Surg. 2004;131(6):1004-6.

21. Urbano AP, Urbano AP, Urbano I. Atrofia óptica e doença de Camurati-Engelmann. Rev Bras Oftalmol. 2001;60(11):822-6.

22. Vanhoenacker FM, De Beuckeleer LH, Van Hul W, Balemans W, Tan GJ, Hill SC, et al. Sclerosing bone dysplasias: genetic and radioclinical features. Eur Radiol. 2000;10:1423-33.

23. Vanhoenacker FM, Janssens K, Van Hul W, Gershoni-Baruch R, Brik R, De Schepper AM. CamuratiEngelmann disease. Review of radioclinical features. Acta Radiol. 2003;44:430-4.

24. Wallace SE, Lachman RS, Mekikian PB, Bui KK, Wilcox WR. Marked phenotypic variability in progressive diaphyseal dysplasia (Camurati-Engelmann disease): report of a four-generation pedigree, identification of a mutation in TGFB1, and review. Am J Med Genet. 2004;129A:235-47. 